\title{
Organochlorine Pesticides in Surface Water of Jiuxi Valley, China: Distribution, Source Analysis, and Risk Evaluation
}

\author{
Zheng Liu, ${ }^{1,2,3}$ Guanlin Zheng $\mathbb{D}^{4}{ }^{4}$ and Zhen Liu ${ }^{1,2,3}$ \\ ${ }^{1}$ School of Environmental Science and Engineering, Xiamen University of Technology, Xiamen, China \\ ${ }^{2}$ Fujian Engineering and Research Center of Rural Sewage Treatment and Water Safety, Xiamen, China \\ ${ }^{3}$ Key Laboratory of Environmental Biotechnology (XMUT), Fujian Province University, Fuzhou, Fujian, China \\ ${ }^{4}$ College of Environment and Ecology, Xiamen University, Xiamen, China \\ Correspondence should be addressed to Guanlin Zheng; golin_zheng@xmu.edu.cn
}

Received 11 October 2019; Accepted 2 January 2020; Published 27 February 2020

Guest Editor: Hangbiao Jin

Copyright (C) 2020 Zheng Liu et al. This is an open access article distributed under the Creative Commons Attribution License, which permits unrestricted use, distribution, and reproduction in any medium, provided the original work is properly cited.

\begin{abstract}
Residual levels of 11 organochlorine pesticides (OCPs) in surface water of Jiuxi Valley were determined during spring and autumn at nine sampling points to assess their contamination and potential risks. The water samples were extracted by solid-phase extraction (SPE), and OCPs were analyzed by gas chromatograph equipped with a ${ }^{63} \mathrm{Ni}-\mathrm{ECD}$ detector. The investigation results indicated that the concentration of total OCPs varied from 4.07 to $13.5 \mathrm{ng} \cdot \mathrm{L}^{-1}$ with an average value of $7.15 \mathrm{ng} \cdot \mathrm{L}^{-1}$ in spring, and from 12.5 to $30.1 \mathrm{ng} \cdot \mathrm{L}^{-1}$ with an average value of $19.9 \mathrm{ng} \cdot \mathrm{L}^{-1}$ in autumn. Jiuxi Valley was slightly contaminated by OCPs, and the concentrations of $\Sigma \mathrm{HCH}$ and $\Sigma \mathrm{DDT}$ in the river were at relatively low levels. HCHs were the main pollutant in spring, and also in autumn, and $\alpha-\mathrm{HCH}$ was the main component of the $\mathrm{HCH}$ isomers at most sampling points. Source analysis indicated that local use of lindane or input of fresh $\gamma-\mathrm{HCH}$ contributed to the presence of HCHs. New inputs were the major sources of DDTs, aldrin, heptachlor, and endrin. The OCP levels of this investigation were within the standard limits set by a majority of the water quality standards and guidelines of China, WHO, European Union, and Canada. However, although the $\gamma$-HCH concentrations at all sampling sites, endrin concentrations at all sampling sites, and $\beta-\mathrm{HCH}$ concentrations at most sampling sites were below the human health water quality standard, and the levels of other tested OCPs $\left(\alpha-\mathrm{HCH}, \mathrm{p}, \mathrm{p}^{\prime}\right.$-DDD, p, $\mathrm{p}^{\prime}$-DDE, p, $\mathrm{p}^{\prime}$-DDT, aldrin, and heptachlor) exceeded the value of EPA-recommended water quality criteria for human health, which indicated potential risks to human health around the region.
\end{abstract}

\section{Introduction}

As common persistent organic pollutants (POPs), organochlorine pesticides (OCPs) have received great attention worldwide due to their high toxicity, chemical durability, and biological concentration [1]. These chemicals were once widely used in agricultural production and pest control universally. Researchers had found OCPs caused great threats to ecosystems and human health $[2,3]$. Despite the prohibition of production and use of these pesticides by many countries in the 1970 s and 1980 s, some OCPs, including hexachlorocyclohexanes (HCHs), dichlorodiphenyltrichloroethanes (DDTs), aldrin, heptachlor, and endrin, were still widely distributed everywhere because of their persistence. China produced a large number of OCPs using for broad spectrum pesticides, medical, and industrial purposes from the late 1940s to the 1980s. From the 1950s to 1983, millions of tons of technical-grade HCHs and DDTs were yielded, accounting for the world output of $33 \%$ and $20 \%$, respectively [4]. Even though production and use of OCPs had been forbidden since 1983, the comparatively high concentrations of residue OCPs were still detected in water and other environmental media.

As an important environmental medium, water bodies play a vital part in the migration and transformation of OCPs. OCPs can enter rivers or lakes via agricultural nonpoint source pollution, industrial wastewater discharge, atmospheric sedimentation, and other ways [5-7]. Although 
most OCPs are difficult to dissolve in water, they are easy to be enriched in organisms by reason of their relatively high octanol-water partition coefficient and have the probability to bioaccumulate through the food chain, causing health risks $[8,9]$. After being discharged into water bodies, they are mainly adsorbed on suspended particles. Under certain circumstances, it will be resuspended after disturbance and become a secondary pollution source $[10,11]$. In addition, OCPs may be involved in atmospheric circulation and migrated to remote places from the source, causing environmental issues at regional and global scale [12].

Jiuxi Valley is located in the east of Xiang'an District, Xiamen City. Xiamen is a beautiful tourist city in southeast China. Jiuxi Valley is $21 \mathrm{~km}$ long and has a drainage area of $101 \mathrm{~km}^{2}$. The nine main branches form a tree-like water system, which flows into the Dadeng sea area in Xindian Town. Jiuxi is called the mother river of Xiang'an District. It flows across the basic farmland protection area of Xiamen. It is a source of farmland irrigation and livestock drinking water. There are also a large number of egrets perched every winter. The government has viewed the Jiuxi Valley as a beautiful ecological green stream. After comprehensive treatment, the water quality of the Jiuxi Valley has been improved, but more information is needed to evaluate the pollution situation and identify the potential risk to human health and ecological risk to aquatic life. As far as we know, this work first reported on the concentrations of OCPs contaminants in Jiuxi Valley.

The major aims of this research work were (1) to investigate the concentrations, spatial distribution, and composition of $11 \mathrm{OCPs}(\alpha-\mathrm{HCH}, \beta-\mathrm{HCH}, \gamma-\mathrm{HCH}, \delta-\mathrm{HCH}$, $\mathrm{p}, \mathrm{p}^{\prime}$-DDD, $\mathrm{p}, \mathrm{p}^{\prime}$-DDE, o, $\mathrm{p}^{\prime}$-DDT, $\mathrm{p}, \mathrm{p}^{\prime}$-DDT, aldrin, heptachlor, and endrin) in surface water of Jiuxi Valley and (2) to investigate the pollution profiles to identify seasonal pollution characteristics, and source apportionment and to evaluate potential risks to human health around the region, thus offering scientific information for efficient strategical environmental management.

\section{Methodology}

2.1. Sampling. Nine sampling points (namely, S1 to S9) along the river were selected, as shown in Figure 1. The collection of water samples at $0.15 \mathrm{~m}$ below the surface of water was carried out in autumn (October 8 to November 8 , 2018) and spring (March 12 to April 12, 2019), and they were stored in precleaned $1 \mathrm{~L}$ brown glass bottles. The suspended matter and impurities in water samples were removed by using $0.45 \mu \mathrm{m}$ fiber glass filters. The extraction was completed within 7 days, and the analysis was completed within 30 days.

2.2. Extraction. The water samples were extracted by solidphase extraction (SPE). In brief, the Florisil SPE cartridges $(1000 \mathrm{mg} / 6 \mathrm{ml})$ were rinsed successively with $5 \mathrm{ml}$ of ethyl acetate, $5 \mathrm{ml}$ of methanol, and $10 \mathrm{ml}$ of ultrapure water. Using vacuum pumping, water samples flowed via the SPE columns at a flow velocity of $10 \mathrm{ml} / \mathrm{min}$. When the

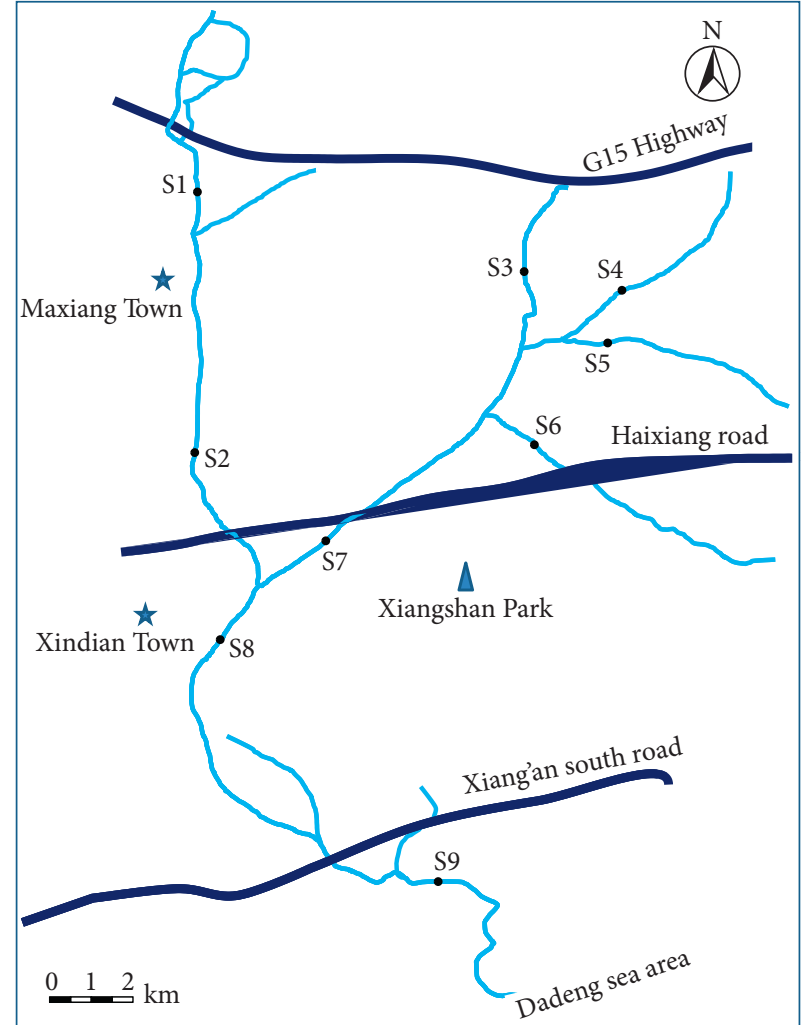

Figure 1: Sampling points of the Jiuxi Valley, Xiamen.

extraction was completed, the OCPs captured in SPE columns were eluted twice with $10 \mathrm{ml}$ of ethyl acetate. Then, anhydrous sodium sulfate (roasted at $300^{\circ} \mathrm{C}$ ) was used to dehydrate the extracts, and then the extracts were concentrated to roughly $0.5 \mathrm{ml}$ with high purity nitrogen streaming. The extracts were spiked with $5.0 \mu \mathrm{l}$ of TCmX (2,4,5,6-tetrachloro-m-xylene) as internal standard and redissolved to $1 \mathrm{ml}$ with $n$-hexane [13]. Finally, the extracts were transferred into vials and kept sealed at $-20^{\circ} \mathrm{C}$ until analysis.

2.3. Chemical Analysis. The OCPs residues were analyzed by using gas chromatograph (Agilent 7890B; $30 \mathrm{~m} \times 0.25 \mathrm{~mm}$ i.d. $\times 0.25 \mu \mathrm{m}$ film thickness, HP-5 capillary column) equipped with a ${ }^{63} \mathrm{Ni}-\mathrm{ECD}$ detector. Samples $(2 \mu \mathrm{l})$ were injected in the splitless injection mode with high purity nitrogen as both carrier gas $\left(1 \mathrm{ml} \cdot \mathrm{min}^{-1}\right)$ and makeup gas $\left(60 \mathrm{ml} \cdot \mathrm{min}^{-1}\right)$. The temperature of the column oven was first set at $100^{\circ} \mathrm{C}$ (with an equilibration time of $2 \mathrm{~min}$ ), raised to $200^{\circ} \mathrm{C}\left(6^{\circ} \mathrm{C} \cdot \mathrm{min}^{-1}\right)$, then to $230^{\circ} \mathrm{C}\left(1^{\circ} \mathrm{C} \cdot \mathrm{min}^{-1}\right)$, and finally reached to $280^{\circ} \mathrm{C}\left(10^{\circ} \mathrm{C} \cdot \mathrm{min}^{-1}\right)$ and retained for $10 \mathrm{~min}$. The injection port and detector temperatures were kept at $280^{\circ} \mathrm{C}$ and $300^{\circ} \mathrm{C}$, respectively. The target OCPs were identified by the retention times matched to each standard. The concentrations of OCPs were acquired using peak area based on a six-point standard curve. In this study, the OCPs analyzed were $\mathrm{HCHs}$ (including $\alpha-\mathrm{HCH}, \beta-\mathrm{HCH}, \gamma-\mathrm{HCH}$, and $\delta$-HCH), DDTs (including p, $\mathrm{p}^{\prime}$-DDD, $\mathrm{p}, \mathrm{p}^{\prime}$-DDE, o, $\mathrm{p}^{\prime}-\mathrm{DDT}$, and $\mathrm{p}, \mathrm{p}^{\prime}-\mathrm{DDT}$ ), aldrin, heptachlor, and endrin. 
TABLE 1: OCPs concentration in surface water from Jiuxi Valley $\left(\right.$ ng $\left.\cdot \mathrm{L}^{-1}\right)$.

\begin{tabular}{|c|c|c|c|c|c|c|}
\hline \multirow{2}{*}{ Compounds } & \multicolumn{3}{|c|}{ Spring, 12.03.2019-12.04.2019 $(n=32)$} & \multicolumn{3}{|c|}{ Autumn, 08.10.2018-08.11.2018 $(n=32)$} \\
\hline & Mean & S. D. ${ }^{\mathrm{a}}$ & Range & Mean & S. D. & Range \\
\hline$\alpha-\mathrm{HCH}$ & 1.45 & 1.63 & $0.120-5.24$ & 7.17 & 3.05 & $4.31-13.0$ \\
\hline$\beta-\mathrm{HCH}$ & 0.968 & 0.798 & $0.509-2.98$ & 3.84 & 2.95 & $2.25-11.5$ \\
\hline$\gamma-\mathrm{HCH}$ & 1.08 & 0.327 & $0.844-1.84$ & 3.16 & 0.854 & $2.42-5.02$ \\
\hline$\delta-\mathrm{HCH}$ & 0.198 & 0.0589 & $0.142-0.312$ & 0.598 & 0.0939 & $0.485-0.756$ \\
\hline$\Sigma \mathrm{HCHs}$ & 3.69 & 2.10 & $1.71-8.12$ & 14.8 & 4.99 & $9.94-23.5$ \\
\hline $\mathrm{p}, \mathrm{p}^{\prime}-\mathrm{DDT}$ & 1.11 & 0.332 & $0.715-1.84$ & 1.48 & 0.403 & $0.849-2.12$ \\
\hline $\mathrm{o}, \mathrm{p}^{\prime}-\mathrm{DDT}$ & 0.904 & 0.421 & $0.247-1.86$ & 1.45 & 0.120 & $0.708-4.13$ \\
\hline $\mathrm{p}, \mathrm{p}^{\prime}-\mathrm{DDD}$ & 0.0612 & 0.0318 & $<0.04-0.128$ & 0.120 & 0.109 & $<0.04-0.316$ \\
\hline $\mathrm{p}, \mathrm{p}^{\prime}-\mathrm{DDE}$ & 0.161 & 0.0680 & $<0.05-0.246$ & 0.283 & 0.165 & $0.0724-0.622$ \\
\hline$\Sigma$ DDTs & 2.23 & 0.615 & $1.19-3.31$ & 3.34 & 1.31 & $1.90-6.23$ \\
\hline Aldrin & 0.736 & 0.524 & $<0.05-1.62$ & 1.28 & 1.63 & $0.213-2.45$ \\
\hline Heptachlor & 0.426 & 0.554 & $<0.04-1.75$ & 0.316 & 0.371 & $0.0634-1.23$ \\
\hline Endrin & 0.063 & 0.0312 & $<0.04-0.110$ & 0.126 & 0.0980 & $<0.04-0.196$ \\
\hline$\Sigma \mathrm{OCPs}$ & 7.15 & 3.08 & $4.07-13.5$ & 19.8 & 6.65 & $12.5-30.1$ \\
\hline
\end{tabular}

Note. Levels below the LOD were assumed to be half the LOD during the data analysis. ${ }^{\text {a}} \mathrm{S}$. D. means standard deviation.

2.4. Quality Control. The analytical quality control scheme included procedural blanks, spiked recovery tests, duplicates, and comparison of standards $[3,6]$. A procedural blank and a standard sample were carried out to check any cross-contamination and repeatability in every set of 9 samples. All blanks were below the limits of detection (LOD). The LOD were set to be triple the standard deviation of the blank. The LOD of target OCPs ranged from 0.04 to $0.3 \mathrm{ng} \cdot \mathrm{L}^{-1}$. The mean recoveries for surrogates $(\mathrm{TCmX})$ were $79.5 \pm 12.2 \%$. Spiked recovery tests of the OCPs using $20 \mathrm{ng}$ of composite standards showed acceptable recoveries ranging from $72.4 \%$ to $105 \%$, with the relative standard deviation less than $\pm 14.1 \%$. The calibration curves had acceptable degree of linearity $\left(R^{2}>0.997\right)$ for all the compounds.

\section{Results and Discussion}

3.1. Temporal Characteristics of OCPs. The seasonal concentrations of the target analytes in the surface water from Jiuxi Valley are presented in Table 1. In the investigation, the total OCPs concentration in spring was different from that in autumn. During the wet season in spring, the total OCPs concentration varied from 4.07 to $13.5 \mathrm{ng} \cdot \mathrm{L}^{-1}$ (mean: $\left.7.15 \mathrm{ng} \cdot \mathrm{L}^{-1}\right)$. During the dry season in autumn, the total OCPs concentration varied from 12.5 to $30.1 \mathrm{ng} \cdot \mathrm{L}^{-1}$ (mean: $\left.19.8 \mathrm{ng} \cdot \mathrm{L}^{-1}\right)$. The difference indicated that the total OCPs concentration in surface water of Jiuxi Valley had seasonal characteristics.

Generally, when the rainfall is relatively high, the land runoff of the farmland will increase the erosion by stream, and some OCPs can be released to water from the soil, resulting in an increase in OCPs [10]. Moreover, turbulence caused by rainfall drainage can also lead to the rerelease of OCPs in suspended sediments [11]. The higher level of OCPs found during autumn might be partially attributed to less water flowing. While in spring, the concentration of OCPs was diluted by the stream owing to rich rainfall, and the soil was not easily eroded because of the large vegetation coverage near the valley and the solidification of asphalt or concrete pavement, which resulted in the relatively lower level of OCPs.

The highest concentrations of OCPs in samples were detected at S5 (30.1 ng. $\mathrm{L}^{-1}$ in autumn) and S6 $\left(13.5 \mathrm{ng} \cdot \mathrm{L}^{-1}\right.$ in spring), and the lowest was at $\mathrm{S} 9\left(4.07 \mathrm{ng} \cdot \mathrm{L}^{-1}\right.$ in spring and $12.5 \mathrm{ng} \cdot \mathrm{L}^{-1}$ in autumn). Sampling point $\mathrm{S} 9$ was connected with a wetland park. Meanwhile, the OCPs were diluted with large amounts of water flowed through S9. While the sampling points S5 and S6 were situated upstream, the vegetation coverage was relatively large, and the water environment was relatively stable. Therefore, the levels of OCPs in Jiuxi Valley were mainly affected by the convergence of stream current and the external environment.

In the upper reaches of the river, the levels of OCPs at S1 and S2 were relatively low in spring and autumn compared to S3, S4, S5, and S6. S1 and S2 were situated in the neighborhoods, where the soil was rarely exposed and the use of OCPs was limited. S3, S4, S5, and S6 were situated in agricultural areas, and the OCPs were used in agriculture pest control for decades, resulting in high residual levels.

In recent years, many OCPs contaminations in surface waters had been reported around the world (Table 2). The investigation showed that Jiuxi Valley was slightly contaminated by OCPs. The concentrations of $\Sigma \mathrm{HCHs}$ and $\Sigma$ DDTs in the river were at relatively low levels. It was difficult to assess large-scale temporal changes in water quality of Jiuxi Valley due to lack of previous studies.

3.2. Seasonal Compositions of OCPs. Changes in the concentrations and compositions of isomers and derivatives of OCPs in the environment keep ongoing, which are connected with the physicochemical properties of the environmental medium and the duration of compounds' exposure [18]. The concentration changes of HCHs and DDTs were studied to identify the seasonal pollution characteristics.

For the individual compounds, four types of $\mathrm{HCH}$ and aldrin were detected at different sampling sites. Four types of DDTs, heptachlor, and endrin were detected at multiple sampling sites. 
TABLE 2: Comparison of $\Sigma \mathrm{HCH}$ and $\Sigma$ DDTs in surface waters $\left(\mathrm{ng} \cdot \mathrm{L}^{-1}\right)$.

\begin{tabular}{|c|c|c|c|}
\hline Location & $\Sigma \mathrm{HCHs}$ & $\Sigma \mathrm{DDTs}$ & Reference \\
\hline Yongding river & $\begin{array}{l}<0.08-13.87 \text { (spring), } \\
<0.08-19.53 \text { (summer) }\end{array}$ & $\begin{array}{l}<0.12-194.34 \text { (spring), } \\
<0.12-88.68 \text { (summer) }\end{array}$ & {$[10]$} \\
\hline Honghu lake & $\begin{array}{l}\text { 0.95-7.04 (dry season), } \\
0.79-4.00 \text { (wet season) }\end{array}$ & $\begin{array}{l}0.06-0.49 \text { (dry season), } \\
0.15-0.82 \text { (wet season) }\end{array}$ & {$[11]$} \\
\hline River Ravi & $\begin{array}{l}2.15-12.73 \text { (postmonsoon), } \\
2.53-6.90 \text { (premonsoon) }\end{array}$ & $\begin{array}{c}\text { 4.09-33.28 (postmonsoon), } \\
3.36-93.15 \text { (premonsoon) }\end{array}$ & [13] \\
\hline Lake Small Baiyangdian & $0.53-6.81$ & N.D. & {$[14]$} \\
\hline Poyang Lake & $4.38-59.65$ & $2.31-33.4$ & {$[15]$} \\
\hline River Hooghly & $8-114$ & N.D. -26 & {$[16]$} \\
\hline River Chenab & $\begin{array}{l}3.6-200 \text { (summer), } \\
<6.7-330 \text { (winter) }\end{array}$ & $\begin{array}{c}0.55-550 \text { (summer), } \\
0.63-580 \text { (winter) }\end{array}$ & {$[17]$} \\
\hline Jiuxi Valley & $\begin{array}{l}1.71-8.12 \text { (spring), } \\
9.94-23.5 \text { (autumn) }\end{array}$ & $\begin{array}{l}1.19-3.31 \text { (spring), } \\
1.90-6.23 \text { (autumn) }\end{array}$ & This study \\
\hline
\end{tabular}

Figures 2, 3(a), and 3(b) showed the seasonal compositions of OCPs. In the spring, $\mathrm{HCH}$ sere the dominant compounds, contributing $51.6 \%$ to the total OCPs, whereas DDTs contributed $31.2 \%$ to the total OCPs. Of all $\mathrm{HCH}$ isomers investigated, $\alpha-\mathrm{HCH}$ was the dominant chemical with the highest level at S6 $\left(5.24 \mathrm{ng} \cdot \mathrm{L}^{-1}\right)$. Among all DDT isomers surveyed, $\mathrm{p}, \mathrm{p}^{\prime}$-DDT was detected with the highest level at S8 $\left(1.84 \mathrm{ng} \cdot \mathrm{L}^{-1}\right)$. In the autumn, $\mathrm{HCH}$ sere also the main pollutant, contributing $72.7 \%$ to the total OCPs, whereas DDTs contributed $16.4 \%$ to the total OCPs. Also, $\alpha-\mathrm{HCH}$ and $\mathrm{p}, \mathrm{p}^{\prime}$-DDT were still in large quantities: $\alpha-\mathrm{HCH}$ made up $48.6 \%$ of the total $\mathrm{HCHs}$, and the maximum concentration was found at S5 $\left(13.0 \mathrm{ng} \cdot \mathrm{L}^{-1}\right)$, whereas $\mathrm{p}, \mathrm{p}^{\prime}$-DDT made up $44.4 \%$ of the total DDTs, and the maximum concentration was detected at S6 (2.12 ng. $\left.\mathrm{L}^{-1}\right)$. p, $\mathrm{p}^{\prime}$-DDE and $\mathrm{p}, \mathrm{p}^{\prime}$-DDD were observed at relatively low levels in most locations.

At most sampling points in the Jiuxi Valley, $\alpha-\mathrm{HCH}$ was the main component of the $\mathrm{HCH}$ isomers, which was mainly because of the composition of the technical-grade $\mathrm{HCH}$. Technical-grade $\mathrm{HCH}$ typical contained 55\%-80\% $\alpha-\mathrm{HCH}$ [19-21], and technical-grade $\mathrm{HCH}$ and DDT were extensively used in the late 60s and 70s in China [11]. Compared to the other three $\mathrm{HCH}$ isomers, $\beta-\mathrm{HCH}$ was nonvolatile and more persistent [10]; therefore, it was more likely to accumulate in the environment and accounted for a relatively large proportion of HCHs in Jiuxi Valley. p, $\mathrm{p}^{\prime}$-DDT was the main pollutant of DDTs mainly because the technical-grade DDT contained approximately 75\% p, $\mathrm{p}^{\prime}$-DDT [22-24]. In addition, o, $\mathrm{p}^{\prime}$-DDT also contributed a relatively large proportion of DDTs. Although DDTs were restricted in 1983, China was still producing DDTs due to the production of dicofol. o, $\mathrm{p}^{\prime}$-DDT and other DDTs remained in the dicofol product as impurities, and o, $\mathrm{p}^{\prime}$-DDT was the most abundant in these impurities [25]. Dicofol was one of the commonly used insecticides in agriculture, and the sale and use of dicofol in China were not completely banned until 2018.

3.3. Sources Identification of OCPs. OCPs participated in various physical and chemical processes after entering the environment. Sources of HCHs and DDTs in surface water might be identified by differences in composition between HCHs or DDTs.

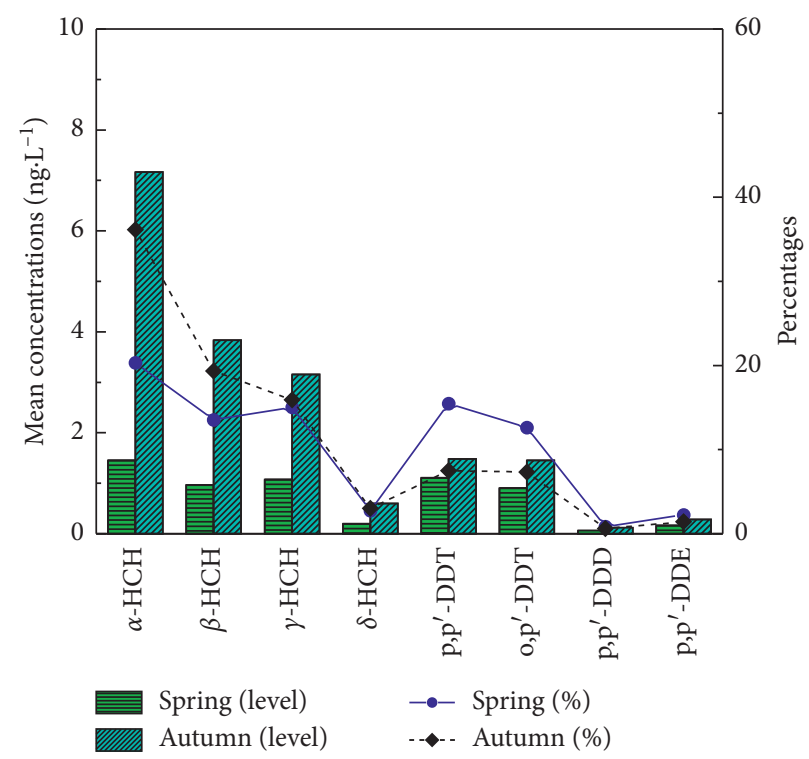

FIgURE 2: Concentrations and percentages of HCHs and DDTs in surface water from Jiuxi Valley.

$\mathrm{HCH}$ in the environment were mainly derived from historical pesticide residues. The main sources of $\mathrm{HCH}$ included technical-grade $\mathrm{HCH}$ and lindane. Technical-grade $\mathrm{HCH}$ typically contained $10-15 \% \gamma-\mathrm{HCH}$, while lindane was mainly compounded of $\gamma-\mathrm{HCH}(>99 \%)$ [26]. The concentration ratio of $\alpha-\mathrm{HCH} / \gamma-\mathrm{HCH}$ was often applied to estimating the source of HCHs. In general, this ratio was in the range of 3-7 for technical-grade $\mathrm{HCH}$. The ratios less than 3 indicated the use of lindane was the main source, and ratios above 7 suggested great distances migration or recirculation of technical-grade $\mathrm{HCH}$ in the environment [26, 27]. Furthermore, $\gamma-\mathrm{HCH}$ could be isomerized into $\alpha-\mathrm{HCH}$ under ultraviolet radiation during long-distance migration, which might make the ratio exceed $7[28,29]$. In this survey, the ratios of $\alpha-\mathrm{HCH} / \gamma-\mathrm{HCH}$ in the surface water of Jiuxi Valley were less than 3, which revealed that the HCHs of Jiuxi Valley were primarily derived from local use of lindane or input of fresh $\gamma$-HCH. Actually, the production, use, import, and export of lindane were not banned until March, 2019 [30]. 


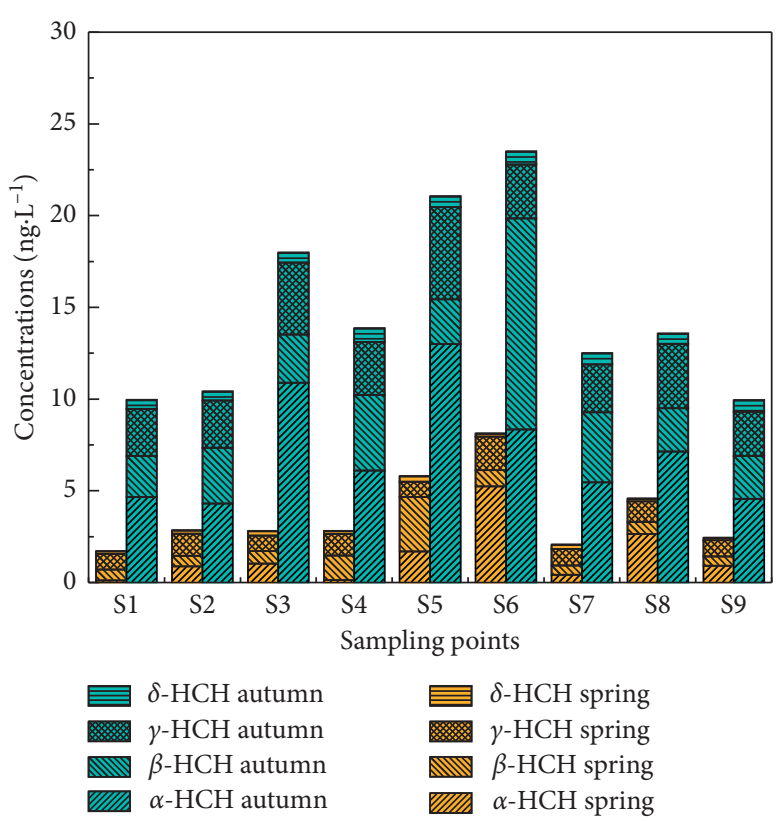

(a)

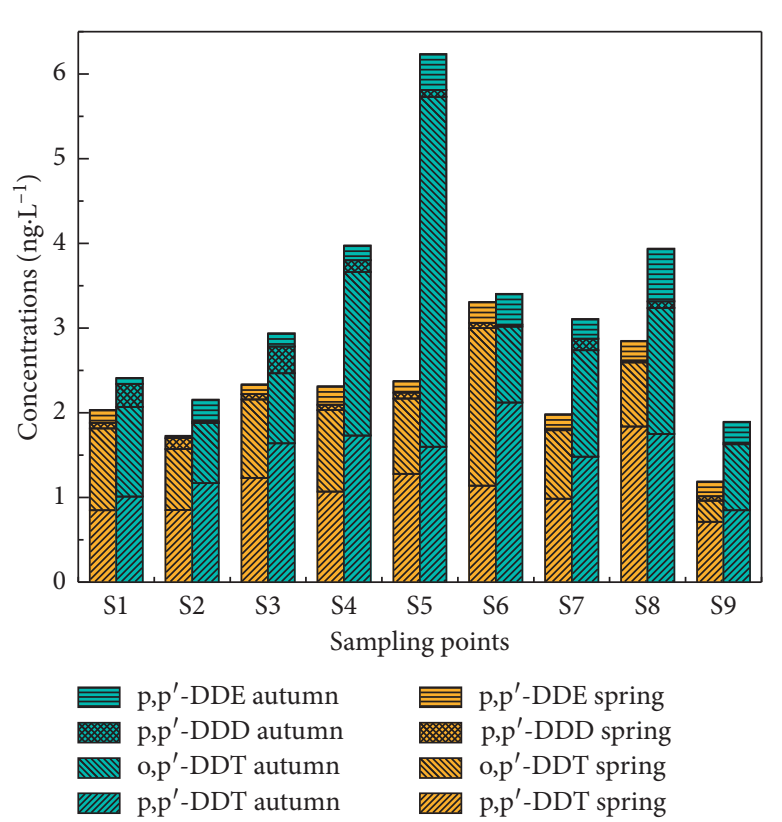

(b)

FIgURe 3: Seasonal compositions and of HCHs (a) and DDTs (b) of sampling points.

TABLE 3: Surface water OCPs concentration standards $\left(\mu \mathrm{g} \cdot \mathrm{L}^{-1}\right)$.

\begin{tabular}{|c|c|c|c|c|c|c|c|}
\hline Country/Organization & $\gamma-\mathrm{HCH}$ & DDTs & Heptachlor & Aldrin & Dieldrin & Endrin & Isodrin \\
\hline China & 2.0 & 1.0 & - & - & - & - & - \\
\hline United States & 0.95 & 1.1 & 0.52 & 3.0 & 0.24 & 0.086 & - \\
\hline European union & - & 0.025 & - & $0.01^{\mathrm{a}}$ & & & \\
\hline Canada & 0.01 & - & - & - & - & - & - \\
\hline
\end{tabular}

Note. "-" denotes "no data"; "a” means the sum of aldrin, dieldrin, endrin, and isodrin.

$\mathrm{p}, \mathrm{p}^{\prime}$-DDT can be degraded to $\mathrm{p}, \mathrm{p}^{\prime}$-DDE and $\mathrm{p}, \mathrm{p}^{\prime}$-DDD under aerobic conditions and anaerobic conditions, respectively $[31,32]$. The concentration ratio of $\mathrm{p}, \mathrm{p}^{\prime}$ $(\mathrm{DDE}+\mathrm{DDD}) / \mathrm{DDT}$ can be applied to estimating the source of DDTs $[33,34] . \mathrm{p}, \mathrm{p}^{\prime}-(\mathrm{DDE}+\mathrm{DDD}) / \mathrm{DDT}>1$ indicated that local DDT residues were the primary source, and less than 1 indicated a new DDT input source $[35,36]$. In this survey, the ratio of $\mathrm{p}, \mathrm{p}^{\prime}-(\mathrm{DDE}+\mathrm{DDD}) / \mathrm{DDT}$ in the surface water of Jiuxi Valley was less than 1 at all sampling points, which suggested that Jiuxi Valley has a new input source for DDT contamination.

Other OCPs (including aldrin, heptachlor, and endrin) had been detected in most water samples of Jiuxi Valley, although they had never been used extensively in the region. These compounds might come from other regions and entered the Jiuxi Valley through atmosphere flow. Although many of these chemicals were forbidden in most areas of the Northern Hemisphere, they are still used in Southeast Asia $[37,38]$. In addition, probably $45-80 \%$ of OCPs migrated to the rest of the earth $[39,40]$.

3.4. Potential Ecological Risk Evaluation. Water quality criteria are critical guidelines on ecological risk evaluation and water environment management. Some water quality standards and guidelines (as shown in Table 3) were applied for the evaluation of OCPs contamination and potential risks of surface water from Jiuxi Valley.

Chinese standards of surface water (GB 3838-2002) specify the limits of $\gamma-\mathrm{HCH}$ and DDT [41]. The results of this investigation indicated that the levels of OCPs in all tested samples were much lower than this standard.

Based on the World Health Organization (WHO) regulations, the limits for the concentration of selected pollutants $\gamma-\mathrm{HCH}, \delta$-HCH, p, $\mathrm{p}^{\prime}$-DDT, p, $\mathrm{p}^{\prime}$-DDE, heptachlor, and aldrin are $2,2,2,20.03,0.03 \mu \mathrm{g} \cdot \mathrm{L}^{-1}$, respectively [42]. The OCPs levels of this investigation were also within the standard limits set by the WHO.

The European Union Directive 2008/105/EC specifies the DDTs concentration limits and the total concentration limits for aldrin, dieldrin, endrin, and isodrin [43]. The residual concentrations of DDTs in the spring and autumn of Jiuxi Valley surface water were below the standard limits. Due to the lack of concentrations of dieldrin and isodrin, it was difficult to ascertain whether the total concentration of the sum of aldrin, endrin, dieldrin, and isodrin exceeded the limits of the instruction.

The Canadian CCME specifies the $\gamma$-HCH concentration limit [44]. The $\gamma$ - $\mathrm{HCH}$ residual concentrations in the spring and autumn of Jiuxi Valley surface water were also below the standard limits. 
TABLe 4: National recommended water quality standards for OCPs $\left(\mu \mathrm{g} \cdot \mathrm{L}^{-1}\right)$.

\begin{tabular}{|c|c|c|c|c|c|c|}
\hline \multirow[b]{2}{*}{ OCPs } & \multicolumn{3}{|c|}{ For human health } & \multicolumn{3}{|c|}{ For aquatic organisms (freshwater) } \\
\hline & $\begin{array}{l}\text { Consumption water } \\
\text { and organism }\end{array}$ & $\begin{array}{l}\text { Consumption } \\
\text { organism only }\end{array}$ & Publication year & Acute toxicity & Chronic toxicity & $\begin{array}{c}\text { Publication } \\
\text { year }\end{array}$ \\
\hline$\alpha-\mathrm{HCH}$ & 0.00036 & 0.00039 & 2015 & - & - & \\
\hline$\beta-\mathrm{HCH}$ & 0.0080 & 0.014 & 2015 & - & - & \\
\hline$\gamma-\mathrm{HCH}$ & 4.2 & 4.4 & 2015 & 0.95 & - & 1995 \\
\hline $\mathrm{p}, \mathrm{p}^{\prime}-\mathrm{DDD}$ & 0.00012 & 0.00012 & 2015 & - & - & \\
\hline $\mathrm{p}, \mathrm{p}^{\prime}-\mathrm{DDE}$ & 0.000018 & 0.000018 & 2015 & - & - & \\
\hline $\mathrm{p}, \mathrm{p}^{\prime}-\mathrm{DDT}$ & 0.000030 & 0.000030 & 2015 & 1.1 & 0.001 & 1980 \\
\hline Aldrin & 0.00000077 & 0.00000077 & 2015 & 3.0 & - & 1980 \\
\hline Heptachlor & 0.0000059 & 0.0000059 & 2015 & 0.52 & 0.0038 & 1980 \\
\hline Endrin & 0.03 & 0.03 & 2015 & 0.086 & 0.036 & 1995 \\
\hline
\end{tabular}

Note. "-" denotes "no data."

As shown in Table 4, EPA developed OCPs criteria of ambient water quality for the environment and human health on the basis of toxicological information [45]. Human health ambient water quality standards represent specific concentration of particular chemicals in water that are not expected to adversely affect human health. Aquatic organism standards represent the highest concentration of particular contaminants in water that are not expected to cause major risks to most aquatic organisms. In this investigation, except for the $\mathrm{p}, \mathrm{p}^{\prime}$-DDT concentration of individual sampling points, the levels of OCPs in Jiuxi Valley were lower than the standard values of chronic toxicity water quality of freshwater aquatic organisms. However, although the $\gamma-\mathrm{HCH}$ at all sampling sites, endrin concentrations at all sampling sites, and $\beta-\mathrm{HCH}$ concentrations at most sampling sites were below the human health water quality standard, and the levels of other tested OCPs $\left(\alpha-\mathrm{HCH}, \mathrm{p}, \mathrm{p}^{\prime}\right.$-DDD,, $\mathrm{p}^{\prime}$-DDE, $\mathrm{p}, \mathrm{p}^{\prime}$-DDT, aldrin, and heptachlor) exceeded the value of EPA recommended water quality criteria for human health. In particular, the aldrin concentration in the autumn at sampling site S6 was 3,822 times the standard value. With these in mind, OCPs pollution might pose ecological risks to physical health in the district and have limited impact on freshwater aquatic organisms.

\section{Conclusions}

In present work, the contamination profiles of 11 OCPs in surface water of Jiuxi Valley were determined. The results showed Jiuxi Valley was slightly contaminated by OCPs, and the level of total OCPs in autumn was higher than that in spring. HCHs were the main pollutant in spring, also in autumn, and $\alpha-\mathrm{HCH}$ was the main component of the $\mathrm{HCH}$ isomers at most sampling points. The HCHs of Jiuxi Valley were mainly derived from the local use of lindane or input of fresh $\gamma$-HCH. New inputs were the major sources of DDTs, aldrin, heptachlor, and endrin. The OCP levels of this investigation were within the standard limits set by most of the water quality standards and guidelines. However, although the $\gamma-\mathrm{HCH}$ concentrations at all sampling sites, endrin concentrations at all sampling sites, and $\beta-\mathrm{HCH}$ concentrations at most sampling sites were below the human health water quality standard, the levels of other tested OCPs
$\left(\alpha-\mathrm{HCH}, \mathrm{p}, \mathrm{p}^{\prime}-\mathrm{DDD}, \mathrm{p}, \mathrm{p}^{\prime}-\mathrm{DDE}, \mathrm{p}, \mathrm{p}^{\prime}-\mathrm{DDT}\right.$, aldrin, and heptachlor) exceeded the value of EPA-recommended water quality criteria for human health, indicating potential risks to human health in the region. In future work, more effort should be directed towards OCPs in sediments to explore migration and transformation of OCPs between water and the sediment.

\section{Data Availability}

The data used to support the findings of this study are available from the corresponding author upon request.

\section{Conflicts of Interest}

The authors declare that they have no conflicts of interest.

\section{Acknowledgments}

This work was supported by the Open Research Fund Program from Fujian Engineering and Research Center of Rural Sewage Treatment and Water Safety (RST201805), Research Climbing Program of Xiamen University of Technology (XPDKQ19015), and Innovation Program of XMUT University Students (201811062190).

\section{References}

[1] W. Wang, J. Bai, G. Zhang et al., "Depth-distribution, possible sources, and toxic risk assessment of organochlorine pesticides (OCPs) in different river sediment cores affected by urbanization and reclamation in a Chinese delta," Environmental Pollution, vol. 230, pp. 1062-1072, 2017.

[2] K. E. Zimmer, M. Montaño, I. Olsaker et al., "In vitro steroidogenic effects of mixtures of persistent organic pollutants (POPs) extracted from burbot (Lota lota) caught in two Norwegian lakes," Science of the Total Environment, vol. 409, no. 11, pp. 2040-2048, 2011.

[3] C. Zhao, H. Xie, J. Zhang, J. Xu, and S. Liang, "Spatial distribution of organochlorine pesticides (OCPs) and effect of soil characters: a case study of a pesticide producing factory," Chemosphere, vol. 90, no. 9, pp. 2381-2387, 2013.

[4] J. Fu, B. Mai, G. Sheng et al., "Persistent organic pollutants in environment of the Pearl River Delta, China: an overview," Chemosphere, vol. 52, no. 9, pp. 1411-1422, 2003. 
[5] D. Pimentel, "Amounts of pesticides reaching target pests: environmental impacts and ethics," Journal of Agricultural and Environmental Ethics, vol. 8, no. 1, pp. 17-29, 1995.

[6] J. Feng, M. Zhai, Q. Liu, J. Sun, and J. Guo, "Residues of organochlorine pesticides (OCPs) in upper reach of the Huaihe River, East China," Ecotoxicology and Environmental Safety, vol. 74, no. 8, pp. 2252-2259, 2011.

[7] U. Ali, J. H. Syed, R. N. Malik et al., "Organochlorine pesticides (OCPs) in South Asian region: a review," Science of the Total Environment, vol. 476-477, pp. 705-717, 2014.

[8] M. Miclean, O. Cadar, E. A. Levei, and D. A. Todea, "Human health risk assessment of organochlorine compounds associated with raw milk consumption in a Romanian industrial area," Italian Journal of Food Science, vol. 30, pp. 116-127, 2018.

[9] M. Miclean, O. Cadar, C. Tanaselia, A. Gog, M. Senila, and I. S. Groza, "Levels of metals and organochlorine compounds in seafood consumed in Cluj-Napoca, Romania," Environmental Engineering and Management Journal, vol. 11, no. 1, pp. 133-140, 2012.

[10] Y. Wang, S. Zhang, W. Cui, X. Meng, and X. Tang, "Polycyclic aromatic hydrocarbons and organochlorine pesticides in surface water from the Yongding River basin, China: seasonal distribution, source apportionment, and potential risk assessment," Science of the Total Environment, vol. 618, pp. 419-429, 2018.

[11] L. Yuan, S. Qi, X. Wu, C. Wu, X. Xing, and X. Gong, "Spatial and temporal variations of organochlorine pesticides (OCPs) in water and sediments from Honghu Lake, China," Journal of Geochemical Exploration, vol. 132, pp. 181-187, 2013.

[12] J. Sheng, X. Wang, P. Gong et al., "Monsoon-driven transport of organochlorine pesticides and polychlorinated biphenyls to the Tibetan Plateau: three year atmospheric monitoring study," Environmental Science \& Technology, vol. 47, no. 7, pp. 3199-3208, 2013.

[13] M. Baqar, Y. Sadef, S. R. Ahmad, A. Mahmood, J. Li, and G. Zhang, "Organochlorine pesticides across the tributaries of River Ravi, Pakistan: human health risk assessment through dermal exposure, ecological risks, source fingerprints and spatio-temporal distribution," Science of the Total Environment, vol. 618, pp. 291-305, 2018.

[14] Y. Wang, W.-J. Wu, W. He, N. Qin, Q.-S. He, and F.-L. Xu, "Residues and ecological risks of organochlorine pesticides in lake small baiyangdian, north China," Environmental Monitoring and Assessment, vol. 185, no. 1, pp. 917-929, 2013.

[15] H. Zhi, Z. Zhao, and L. Zhang, "The fate of polycyclic aromatic hydrocarbons (PAHs) and organochlorine pesticides (OCPs) in water from Poyang Lake, the largest freshwater lake in China," Chemosphere, vol. 119, pp. 1134-1140, 2015.

[16] P. Chakraborty, S. N. Khuman, S. Selvaraj et al., "Polychlorinated biphenyls and organochlorine pesticides in river brahmaputra from the outer himalayan range and river hooghly emptying into the bay of bengal: occurrence, sources and ecotoxicological risk assessment," Environmental Pollution, vol. 219, pp. 998-1006, 2016.

[17] S. A.-M.-A.-S. Eqani, R. N. Malik, A. Katsoyiannis et al., "Distribution and risk assessment of organochlorine contaminants in surface water from River Chenab, Pakistan," Journal of Environmental Monitoring, vol. 14, no. 6, pp. 1645-1654, 2012.

[18] V. Y. Tsygankov, "Organochlorine pesticides in marine ecosystems of the far eastern seas of Russia (2000-2017)," Water Research, vol. 161, pp. 43-53, 2019.

[19] J. A. Placencia and S. Contreras, "Organochlorine pesticides in surface waters from Reloncaví Fjord and the inner sea of
Chiloé ( $\left.39.5^{\circ} \mathrm{S}-43^{\circ} \mathrm{S}\right)$, Chilean Patagonia," Marine Pollution Bulletin, vol. 126, pp. 389-395, 2018.

[20] X. Qiu, T. Zhu, J. Li et al., "Organochlorine pesticides in the air around the Taihu Lake, China," Environmental Science \& Technology, vol. 38, no. 5, pp. 1368-1374, 2004.

[21] A. Mahmood, R. N. Malik, J. Li, and G. Zhang, "Levels, distribution pattern and ecological risk assessment of organochlorines pesticides (OCPs) in water and sediments from two tributaries of the Chenab River, Pakistan," Ecotoxicology, vol. 23, no. 9, pp. 1713-1721, 2014.

[22] R. F. Bopp, H. J. Simpson, C. R. Olsen, R. M. Trier, and N. Kostyk, "Chlorinated hydrocarbons and radionuclide chronologies in sediments of the Hudson River and estuary, New York," Environmental Science \& Technology, vol. 16, no. 10, pp. 666-676, 1982.

[23] Y. Zhu, H. Liu, Z. Xi, H. Cheng, and X. Xu, "Organochlorine pesticides (DDTs and HCHs) in soils from the outskirts of Beijing, China," Chemosphere, vol. 60, no. 6, pp. 770-778, 2005.

[24] Y. Yu, Y. Li, Z. Shen et al., "Occurrence and possible sources of organochlorine pesticides (OCPs) and polychlorinated biphenyls (PCBs) along the Chao River, China," Chemosphere, vol. 114, pp. 136-143, 2014.

[25] X. Qiu, T. Zhu, B. Yao, J. Hu, and S. Hu, "Contribution of dicofol to the current DDT pollution in China," Environmental Science \& Technology, vol. 39, no. 12, pp. 4385-4390, 2005.

[26] J. Gao, H. Zhou, G. Pan, J. Wang, and B. Chen, "Factors influencing the persistence of organochlorine pesticides in surface soil from the region around the hongze lake, China," Science of the Total Environment, vol. 443, pp. 7-13, 2013.

[27] Y. F. Li, D. J. Cai, and A. Singh, "Technical hexachlorocyclohexane use trends in China and their impact on the environment," Archives of Environmental Contamination and Toxicology, vol. 35, no. 4, pp. 688-697, 1998.

[28] L. A. Barrie, D. Gregor, B. Hargrave et al., "Arctic contaminants-sources, occurrence and pathways," Science of the Total Environment, vol. 122, no. 1-2, pp. 1-74, 1992.

[29] K. L. Willett, E. M. Ulrich, and R. A. Hites, "Differential toxicity and environmental fates of hexachlorocyclohexane isomers," Environmental Science \& Technology, vol. 32, no. 15, pp. 2197-2207, 1998.

[30] Ministry of Ecology and Environment of the People's Republic of China (MEE), Notice on the Prohibition of the Production, Circulation, Use and Import and Export of Persistent Organic Pollutants, MEE Web, Beijing, China, 2019, http://www.mee.gov. cn/xxgk2018/xxgk/xxgk01/201903/t20190312_695462.html.

[31] R. Bossi, B. Larsen, and G. Premazzi, "Polychlorinated biphenyl congeners and other chlorinated hydrocarbons in bottom sediment cores of Lake Garda (Italy)," The Science of The Total Environment, vol. 121, pp. 77-93, 1992.

[32] T. Heberer and U. Dünnbier, "DDT metabolite bis(chlorophenyl)acetic acid: the neglected environmental contaminant," Environmental Science \& Technology, vol. 33, no. 14, pp. 2346-2351, 1999.

[33] T. F. Bidleman, "Atmospheric transport and air-surface exchange of pesticides," Fate of Pesticides in the Atmosphere: Implications for Environmental Risk Assessment, vol. 115, no. 1-4, pp. 115-166, 1999.

[34] K. T. Lee, S. Tanabe, and C. H. Koh, "Distribution of organochlorine pesticides in sediments from Kyeonggi Bay and nearby areas, Korea," Environmental Pollution, vol. 114, no. 2, pp. 207-213, 2001. 
[35] K. Jaga and C. Dharmani, "Global surveillance of DDT and DDE levels in human tissues," International Journal of Occupational Medicine and Environmental Health, vol. 16, no. 1, pp. 7-20, 2003.

[36] X. Wang, N. Ren, H. Qi, W. Ma, and Y. Li, "Levels, distributions, and source identification of organochlorine pesticides in the topsoils in Northeastern China," Journal of Environmental Sciences, vol. 21, no. 10, pp. 1386-1392, 2009.

[37] M. Grung, Y. Lin, H. Zhang et al., "Pesticide levels and environmental risk in aquatic environments in China-a review," Environment International, vol. 81, pp. 87-97, 2015.

[38] P. I. Devi, J. Thomas, and R. K. Raju, "Pesticide consumption in India: a spatiotemporal analysis," Agricultural Economics Research Review, vol. 30, no. 1, pp. 163-172, 2017.

[39] F. Wania, J. Axelman, and D. Broman, "A review of processes involved in the exchange of persistent organic pollutants across the air-sea interface," Environmental Pollution, vol. 102, no. 1, pp. 3-23, 1998.

[40] K. Breivik, R. Alcock, Y. F. Li, R. E. Bailey, H. Fiedler, and J. M. Pacyna, "Primary sources of selected POPs: regional and global scale emission inventories," Environmental Pollution, vol. 128, no. 1-2, pp. 3-16, 2004

[41] Ministry of Ecology and Environment of the People's Republic of China, Environmental Quality Standards for Surface Water (GB 3838-2002), MEE Web, Beijing, China, 2002, http://kjs.mee.gov. cn/hjbhbz/bzwb/shjbh/shjzlbz/200206/t20020601_66497.shtml.

[42] D. J. Hamilton, Á. Ambrus, R. M. Dieterle et al., "Regulatory limits for pesticide residues in water (IUPAC technical report)," Pure and Applied Chemistry, vol. 75, no. 8, pp. 1123-1155, 2003.

[43] European Union, Directive 2008/105/EC of the European Parliament and of the Council of 16 December 2008, EU Publications Web, Brussels, Belgium, 2008, https://eur-lex.europa.eu/legalcontent/EN/TXT/?uri=CELEX\%3A32008L0105.

[44] Canadian Council of Ministers of the Environment (CCME), Canadian Environmental Quality Guidelines, CCME Web, Winnipeg, Canada, 2015, http://st-ts.ccme.ca/en/index.html.

[45] United States Environmental Protection Agency (USEPA), Current Water Quality Criteria Tables, USEPA Web, Washington, DC, USA, 2015, https://www.epa.gov/wqc. 